\title{
Exploration and Research on the Inheritance and Innovation Mode of Shadow Art in South Henan
}

\author{
Ling Yang \\ Huanghe Science and Technology College \\ Zhengzhou, China
}

\begin{abstract}
With the continuous expansion of globalization trend, the artistic forms inevitably combine each other within the worldwide scope, from which the single regional shadow play products of south Henan is separated, gradually disappearing and replaced by international design languages, artistic works and modern life idea. Whether from the view of design modeling or from local language, traditional folk shadow art is deeply rooted in the connotation of folk culture, and if the regional shadow art in south Henan is to be protected and inherited, there must be innovation of new regenerated art works, so as to continue its inheritance and development in combination with other arts.
\end{abstract}

Keywords—shadow art in South Henan; inheritance and innovation; exploration and research

\section{INTRODUCTION}

Chinese traditional culture and art has a history of 5,000 years. As the saying goes: Each place has its own way of supporting its own inhabitants, and the ordinary land of Luoshan, Nanyang, Gushi, Shangcheng in the central plain have bred their own folk customs, meanwhile they also gave birth to numerous colorful folk arts - the art of shadow play; as an artistic treasure of our great nation, an indispensable part of civilization development, one characteristic of folk arts as well as an intangible cultural heritage, the art of shadow play deserves research and conservation by the author.

\section{CURRENT DEVElopment OF SHAdOW ART IN SOUTH HENAN}

As a traditional folk art, shadow play in south Henan enjoys bright colors, rich content and unique models; besides, the art of shadow play is the pre-existence of modern cartoon and animation according to historical arguments and expert analysis. The art of shadow play can be classified into multiple subject categories of art such as folk literature, music, drama, opera, painting and craft, etc. However, with the development of economy, the influence of social development and living environment, the impact of new cultures and foreign cultures as well as changes in human lifestyles, the shadow play in south Henan can hardly find a suitable developmental path in merging into mortal world of the 21 st century.

\section{A. Influence of Ecological Environment on the Shadow Play in South Henan}

Situated at the boundaries of Hubei, Henan and Anhui Provinces, the art of shadow play with unique molding styles in south Henan region is gradually crowded out subject to changes in people's living environment. Meanwhile, the normal performance time and influence sphere of shadow play in south Henan are both shrinking day by day, the operation of shadow play troupes is stagnant and development of the whole shadow play industry is having difficulty in taking a step. Viewing from the angle of ecological environment of shadow play in south Henan, there is not much living space and environment; the following points are summarized:

Firstly, the performance of a shadow play is a drama on the curtain, which is a relatively simple and prompt artistic performance that serves for public entertainment. In the increasingly widespread and fast-paced urbanization life, such kind of form is not able to fully satisfy the intermittent and leisurely living and entertaining patterns of modern people. People tend to enjoy their own recreation in a relatively private space, while the live show of a shadow play performs a single form of artistic performance; since young people can enjoy the kaleidoscopic world and all kinds of joy without leaving home, shadow plays can not meet the tastes of modern youth thus resulting in narrow audience coverage and shrink of living space.

Secondly, shadow plays in south Henan are mostly located in relatively remote rural areas and confined by regions. The range of audiences is greatly restricted due to the dialect of language carrier and regional limitations. By virtue of the income and low status, nobody is willing to learn about it.

Thirdly, ancient arts like shadow plays have been passed from mouth to mouth over hundreds of years, and nowadays many young people study and work away from home all year round, unwilling to learn this old-fashioned art, thus giving rise to a gap of artist cultivation since no one can operate performances and act plays.

\section{B. Impact of Contemporary Culture on the Shadow Play in South Henan}

From the view of culture itself, the cultural background of shadow play in south Henan and Chinese traditional 
culture and folk tales, legends, etc. all exert a profound influence on people's life. The development of shadow play in south Henan also drives the development of folk culture in south Henan and adds enrichment of people's life; but far apart from changing social progress, growth in people's living standards, popularization of cultural knowledge in the whole society, lost in transmission of shadow play artists, fusion of shadow play art and culture.

Firstly, shadow play carries a superstitious mythological color due to the influence from historic culture of shadow play and drawing materials from historical legends and romaunts. With advanced science, technology and medical treatment, the enhancement in changing and understanding of people's psychological demand coverage, the social functions of shadow plays are weakened and shadow plays are gradually being paid less attention.

Secondly, new knowledge structure, invasion of Western culture, development and application of high technologies, plentiful machine duplicating programs are gradually replacing the traditional manual workshops.

\section{INHERITANCE OF SHADOW ART IN SOUTH HENAN}

\section{A. Combining Modern Technologies}

Through the application of modern electronic digital and other high-tech performance forms combined with lighting, stage design and sound, the art of shadow play is added with more attractiveness and appeal therefore catering to more people; for instance, the shadow play version of "Welcome to Beijing" showed on 2008 Beijing Olympic Games was integrated with new sound and lighting effects which not only has modern artistic fashion but also not lack of traditional artistic atmosphere.

\section{B. Cultivating Successors of Shadow Play}

Propagandize shadow play in south Henan, especially aiming at school students, put forth effort in advocating the roles and functions of shadow play, allowing students to learn the creating methods, modeling features and performing arts of shadow plays by themselves, to cultivate their interests in the art of shadow play and excavate talents.

\section{Improving Shadow Play Program and Performing conditions}

Improve people's faith habits for shadow plays and continue the traditional festival performance modes, extend performance time, select more modernized performance venues, and choose the program in accordance with public age and performing sites.

\section{Protection of Shadow Art in SOUth Henan}

\section{A. Strengthening Governmental Functions}

Conduct classification and filing of folk arts from the angle of multiple subjects such as folklore, history, drama, fine arts, etc. and by using various recording methods like text, photography, audio and video recording, etc. and establish shadow play museums. Carry out trainings for shadow play artists on various aspects of knowledge and offer financial support as well as protect old artists.

\section{B. Enhancing Economic Benefits of Shadow Play}

The greatest difficulty of shadow play in south Henan faces is economic benefits, and a long-term development can be achieved only by truly putting shadow play into the market. Modern means of improvement and production can be adopted such as: promote regional characteristics in accessories market, clothing and tourist areas in south Henan, to let more people take it out of doors thus gaining economic benefits while winning the potential for its sustainable development. Make full use of tourist attractions and scenic spots to create local characteristic culture brands.

\section{Basing on the Culture and Rreturning the Life}

Set up folk art museums at city and county regions of south Henan and incorporate them into local teaching materials. As an educational base of promoting the art of shadow play and culture, shadow play art can also be incorporated into local teaching materials to achieve effective inheritance. Organize shadow art troupes to let the art of shadow play enter classroom activities, namely enter craft classes, motivate the interest and hobbies of youngsters regarding the art of shadow play and erect the sense of pride in learning excellent local culture. If the functions of life and use are to be maintained, they should engage in modern life as well as fields of design, creation and education. Shadow play art should be more lifestyle and functional instead of being a pure static art.

\section{Making Dynamic and Static Combination based on Shadow Play's Characteristics}

Taking advantage of the "National Intangible Cultural Museum" in our country, we can play the production and performance techniques and methods of virtual and animated shadow play when displaying static shadow play pictures, plan the specific areas in urban streets, shopping malls, libraries and exhibition halls and combine the special performing forms of shadow play to make different groups reflect the performance, operation and process of shadow play. We shall avoid letting shadow play rest on static state to become a "specimen" and lose its social functions and artistic values like other folk arts.

\section{InNOVATIVE APPLICATION OF THE ART OF SHADOW PLAY}

\section{A. Innovation of Shadow Play Art in Modern Design}

1) Embodiment of shadow play modeling features in television animation: Its footprints can be found in the field of television animation, both the old sculptor Zhao Shutong and the Dean of China Academy of Art Xu Jiang regard that the inspiration derives from the ancient and traditional Chinese art of shadow play. Making a general survey from the functions, modeling art and performing techniques of shadow play to the emergence of film, television and animation, the latter enables television animation to be born out of the art of shadow play by assimilating the elements 
and experience of the former. Taking the success of Chinese animation "The Monkey King" as an example, it absorbed the nutrition of shadow play from all aspects and manifested characteristics of shadow plays. "Three Monks" and "Little Tadpole Searching for Mommy? also won worldwide and international recognition by utilizing traditional resources. The shadow play dance of "Golden Sunset" on Spring Festival Gala Evening was a form of simulating and animating the models and actions of shadow play by real persons, which endowed a sense of life and increased spatial effect. The modeling of shadow play enables people to draw much value of shadow play. Shadow play not only inspired many animations but will also boost the development of television animation. The following innovative proposals are put forward according to the influence exerted by shadow play on television animation:

a) Application of modern video and audio technology: To start with, the screen can be multi-faceted, multi-layered, multi-windowed and mobile flexible, which means to control the screen according to the needs of plot and scene and display different scenarios by different screens; in the second place, diversiform designs can be conducted by using twodimensional and three-dimensional software with adoption of plane background or three-dimensional background under different colors, styles and effects to assist plot and heighten atmosphere; besides, simulating sounds with audio, multimedia, etc. can add vividness and splendor to the performance of shadow play.

b) Application of digital technology: By applying digital technology, the role models of shadow play can be enriched and the figures can be more plentiful and vivid; secondly, abundant changes in facial expression and inner activities of characters can be presented so as to resonate with audiences; in addition, changes in multiple angles of local lens can be achieved to form a contrast with other role models and enrich the scenes.

c) Combination with the Internet: By fabricating cartoons and online games containing features and models of shadow play via digital technology, more youngsters will be able to use and view them. Many vivid, lively and personalized virtual expression avatars with features of shadow play can also be designed. Besides, when using QQ, Fetion, SMS and MMS, we can also express feelings via traditional folk artistic forms through network.

2) Combination of shadow play modeling features and modern graphic design:

a) Extraction of elements: There are many excellent manifestations of aesthetic ways and thinking modes of Chinese traditional culture in modern graphic design; in modern graphic design, there are good embodiment and application of the profound cultural heritage contained in Chinese traditional culture. It is actually a symbol of enjoying life to transform and apply implications in packaging by applying shadow play modeling into packaging plus graphic design techniques and principle of form beauty. There are many elements and figures in shadow play that are worthy of applying and referencing in graphic design, and conveys people with different emotions and give prominence to characteristics and representativeness of regions.

The modeling of graphic design and shadow play are both displayed in plane two-dimensional spaces which belong to the same design category, such as plane logo design, packaging design, advertising design, recognition system, covers of publications and illustration design etc. But the traditional producing methods and time limits of shadow play still bring our life a lot of inconvenience. If we want to retain traditions while bringing up innovation, we must put shadow play elements into modern graphic design supplemented by computer technical processing and modern technology in order to realize combination of design and traditional art.

b) Reference of techniques: The modeling of shadow play figures are generally engraving models of frontage and profile, and there may occur the case of different angles like horizontal view, overhead view, side view and upward view being integrated on one plane in the artistic modeling of a same shadow play in order to produce stereo sense. Graphic design also applies this technique to design outstanding works.

The yin and yang engravings, mutualism of blankness and fullness of shadow play also lay ideological and aesthetic foundations for the generation of folk fine arts. The visible part of the figure is "full" space and invisible blank part is "blank" space. "Reckon blank as inked, virtual rather than real" refers to the corresponding relationship of blankness and fullness of figures. Modern graphic design should realize distinction between the primary and essential as well as being concise and clear during composition and design under the overall aesthetic ideas. In graphic design, designers skillfully use the design language of "blankness". "Blankness" is an imaginary space formed by careful conception of designers in creative design following the reverse thinking rules in designing image spacing. The engraving blankness in folk shadow play has strong enlightenment in the form and style of modern design.

\section{CONCLUSION}

From the sluggish development of shadow play in south Henan to the worrying predicament, another proposal of inheritance and innovation methods and new modes may be make shadow play become a new vital force, still closely linking with our life. Through innovative application of shadow play, we can find that visual language in folk shadow play plays a strong role in enlightening us for the forms and styles of modern design. Shadow play modeling also exerts enlightenment on artistic category including modern design, animation, video and audio, etc.; folk shadow art is an ethnic art form that integrates modeling, engraving, craft and coloring which carries strong ethnic culture and bears artistic value above ethnic groups. If the inheritance of traditional shadow play art shall go farther, there must appear new works to adapt to social development and the life of people. 


\section{REFERENCES}

[1] Li Wei, Representation of Chinese Shadow Plays [N]. China Population News, 2003.

[2] Wei Liqun, History of Chinese Shadow Play Art [M]. Beijing: Cultural Relics Publishing House, 2007.

[3] Luoshan County Annals of Luoshan County Government [M]. Zhengzhou: Henan People's Publishing House, 1987.

[4] Zuo Hanzhong, Chinese Folk Art Modeling [M]. Changsha: Hunan Fine Arts Publishing House, 2006.

[5] Li Yuezhong, Chinese Shadow Play and Folklore [M]. Zhengzhou: Daxiang Publishing House, 2010. 